\title{
Article
}

\section{Breaking down boundaries? Exploring mutuality through art-making in an open studio mental health setting}

Lewis, Lydia and Spandler, Helen

Available at http://clok.uclan.ac.uk/26632/

Lewis, Lydia and Spandler, Helen ORCID: 0000-0002-0970-5141 (2019)

Breaking down boundaries? Exploring mutuality through art-making in an

open studio mental health setting. Journal of Applied Arts and Health, 10 (1).

pp. 9-23. ISSN 2040-2457

It is advisable to refer to the publisher's version if you intend to cite from the work.

http://dx.doi.org/10.1386/jaah.10.1.9_1

For more information about UCLan's research in this area go to http://www.uclan.ac.uk/researchgroups/ and search for <name of research Group>.

For information about Research generally at UCLan please go to http://www.uclan.ac.uk/research/

All outputs in CLoK are protected by Intellectual Property Rights law, including Copyright law. Copyright, IPR and Moral Rights for the works on this site are retained by the individual authors and/or other copyright owners. Terms and conditions for use of this material are defined in the policies page.

\section{CLoK}

Central Lancashire online Knowledge www.clok.uclan.ac.uk

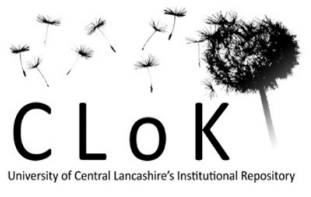




\title{
Breaking down boundaries? Exploring mutuality through art-making in an open studio mental health setting
}

Lydia Lewis, University of Wolverhampton

Helen Spandler, University of Central Lancashire

\begin{abstract}
Community-based participatory arts projects have been shown to promote well-being and mental health recovery. One reason for this is because they provide opportunities for mutuality - connectedness to others and different kinds of sharing and reciprocity. Yet research into mental health arts projects has not focused on shared creative practice between participants/members and practitioners. This article reports on qualitative research in an arts and mental health organization employing an open studio approach in which art therapists made art alongside members. It explores the possibilities for, and tensions associated with, generating mutuality between studio managers and members through this approach.

Conducted from a critically engaged, feminist sociological perspective, the study encompassed an analytical focus on power, especially gender relations. Findings are presented along three themes: (de)constructing and obscuring relational asymmetries; mutual acceptance and its limits; and maintaining, working with and challenging 'boundaries'. Implications for applied arts and mental health practice are highlighted.
\end{abstract}

\section{Keywords}

mental health

creative practice

gender 
mutuality

therapeutic community

open studio

\section{Introduction}

This article explores mutuality between members and workers in a community-based mental health arts setting using an open studio approach. It explores the possibilities for generating mutuality through art-making together within this setting and examines some challenges and tensions associated with this way of working. Adopting a critical, feminist sociological lens that takes account of the broader social context and power inequities, the discussion engages with the complex construction of socio-political relations through this shared art-making practice and highlights the significance of gender relations for understanding the social setting.

The open studio approach of the setting studied blends a therapeutic community style working with arts education and offers people with severe and enduring mental health needs an opportunity to develop their creativity and exhibit their artwork as members of a working art studio. Trained art therapists (called studio managers) make art alongside service user artists (called members), who all develop their own artwork, and sometimes produce collective artwork. The art studio was broadly in keeping with therapeutic community principles in which 'the community itself, through self-help and mutual support, is the principal means for promoting personal change' and everyone involved contributes to running the community (Australasian Therapeutic Communities Association 2017). However, an important element of the organization's approach was the primary emphasis on art-making rather than therapy. 
When we refer to 'mutuality' we are specifically referring to connectedness to others and different kinds of sharing and reciprocity between people in the art studio, which included members, studio managers and volunteers. The research conducted in this setting was part of a larger study on the generation of mutuality through creative practices in community contexts and implications for mental health and wellbeing (Lewis et al. 2016). This, in turn, was part of a research programme called Creative Practice for Mutual Recovery (CPMR) which examined mutuality, mental health recovery and well-being in relation to a range of arts and humanities practices (see Crawford et al. 2018). The concept of 'mutual recovery' indicates a broadening of the usual evaluative lens to explore how promoting connectedness, sharing and reciprocity between arts project participants may not only affect recovery for those seeking help with mental health issues but also have well-being benefits, and possibly even 'disbenefits', for others involved, particularly mental health practitioners.

Currently, a small number of studies demonstrate mutual benefits for clients/service users and health care workers as co-participants in creative arts programmes in mental health contexts. A common theme is the way in which participation can break down barriers and build bridges between self and others (e.g. Ascenso et al. 2018; Callahan et al. 2017; Froggett and Little 2012; Perkins et al. 2016; Sapouna and Pamer 2016; Saavedra et al. 2017). Mutuality can help participants move beyond professional boundaries and traditional hierarchical barriers between 'us and them', working to help level out social distinctions and to equalize and improve relationships as positions of organizational status are (at least temporarily) put aside and new connections and insights are forged. Transforming perceptions of one another, deepening understanding of self and others, and gaining a sense of shared enjoyment and fun are particularly strong themes.

This process may also be challenging for participants, including workers, at different points in time, something indicated in more deliberately politicized attempts to disrupt 
traditional relations of power and control through such interventions (e.g. Noble 2005). Arts projects can thus be both pleasurable and difficult spaces, offering significant challenges for people engaging in creative work, both in relationship to oneself and one's artwork and in negotiations with others (Parr 2012; Stickley et al. 2007).

Research into mental health participatory arts in community settings more specifically often highlights the important role of mutuality among participants (Callard and Friedli 2005; Goldie 2007; Parr 2006; Secker et al. 2007; Stickley 2010), and sometimes how the settings can be characterized by a collaborative, non-hierarchical relationship between tutor and participants (Swindells et al. 2013). However, this research has rarely highlighted mutual creativity between mental health or arts practitioners, and participants, 'service users' or members - their engagement in art-making together as a shared practice. While a few studies (e.g. Sapouna and Pamer 2012, 2016) have drawn attention to this, unsurprisingly, the focus of research in these settings has been primarily the individual mental health benefits to the participants of these (i.e. people with designated mental health problems).

Indeed, the well-being needs of practitioners are often overlooked or marginalized in research into participatory arts, and mental health research generally, and there is a dearth of research into the need, especially among art therapists, for personal creativity to support and develop people in their roles (Iliya 2014). Exceptions include the Mental Health Foundation evaluation of arts and mental health projects (Goldie 2007), which suggested that the arts and mental health workforce required additional support and training for both their artistic and mental health practice. Similarly, Brown (2012) suggested that the work of mental health arts practitioners can be especially stressful and requires support, including enabling them to pursue their own artistic vocation. Some arts projects have this built into their practice, but there has been little research explicitly exploring the processes and, in particular, the 
challenges of shared engagement in creative practice among participants and practitioners, and the outcomes of this shared practice for the respective parties.

Furthermore, the operation or challenging of traditional social structural power relations (of gender, class, race, ethnicity and so forth) in participatory arts spaces remains a lacuna in research in this area. Arts participants tend to be portrayed as homogenized groups (as 'arts participants', 'artists' or 'mental health service users') with little consideration of social differences and inequalities and the relevance of these for mental health or for arts and mental health practice.

Therefore, there is a need for further, critical exploration of mutuality in relation to creative practices that aim to support recovery, not least 'to more fully illuminate the complex social relationships, including issues of power, that are intertwined within creative practice' (Perkins et al. 2016: 15). As such, this article addresses the following research question: what are the possibilities for, and tensions associated with, generating mutuality between members and studio managers through art-making together in a community-based mental health arts setting employing an open studio-based therapeutic community approach? It highlights some of the social mechanisms of shared art-making practice in a mental health participatory arts setting and considers (potential) limiting factors to the generation of mutuality in such a setting, and how these may be negotiated. After presenting the research methodology, the findings are set out along three themes: (de)constructing and obscuring relational asymmetries; mutual acceptance and its limits; and maintaining, working with and challenging 'boundaries'. The discussion and conclusion include consideration of how the findings relate to wider research on well-being and recovery and implications for the practice of shared art-making in open studio mental health settings.

\section{Methodology}


As already described, this article draws on data from one setting in a wider study (Lewis et al. 2016).- This setting was an art studio organization for people struggling with mental health difficulties that was facilitated by art therapists ('studio managers'), most of whom were also trained artists. The organization was purposively sampled as it employed an open studio model in which art therapists made art alongside members. Consequently, it was considered a potentially rich site for studying mutuality between practitioners and participants in a mental health arts setting in a community context.

Members, many of whom had backgrounds in art or related areas and had long-term mental health issues, attended the art studio on allocated week days to undertake self-directed artwork across multiple media (although painting and drawing were most common). Generally, there were eight to twelve members present on any given day. In addition, there were exhibiting opportunities and members took part in events and group gallery visits. Formal structures for member involvement comprised monthly forum meetings and member representatives. There were two studio managers in attendance each day and sometimes an additional volunteer or student art therapist. The studio managers worked part-time, often so that they could also pursue their personal artwork outside this setting.

The study was qualitative in approach and constructivist in nature, focusing on understanding the social dynamics of the setting, rather than being concerned with causal relationships between arts practices and health outcomes. It used a mixed-methods design with methods encompassing participant observation (fifteen sessions, across three different week days), individual face-to-face interviews with members $(n=12)$ and three paired interviews with studio managers and one individual interview with a volunteer studio manager who was a newly qualified art therapist $(n=7)$. Following consultation with members, individual interviews were the preferred method. The studio managers were interviewed in pairs who worked together as this was considered by the researchers to fit with 
a reflective practitioner approach that allowed for in-depth exploration of issues (Brookfield 2005). The individual interviewee was an additional volunteer member of staff present on one of the days when the studio manager interviews were conducted.

Demographic information about the participants in provided in the table below.

Table 1: Participant demographic information.

\begin{tabular}{|c|c|c|c|}
\hline & & Members & Studio \\
& & & managers \\
\hline Sex & Female & 9 & 5 \\
\hline Age range & Male & 3 & 2 \\
& $31-40$ & 3 & 3 \\
& $41-50$ & 4 & 3 \\
& $51-60$ & 1 & 0 \\
\hline Ethnic & $61-70$ & 11 & 5 \\
\hline \multirow{2}{*}{ classification } & White: British & 0 & 1 \\
& Asian other & 1 & 1 \\
\hline
\end{tabular}

Further socio-demographic information gleaned from member participants included highest educational qualifications to date. Here, three stated Bachelor's Degrees, with two specifying Fine Art, one stated a Fine Art Diploma, one an Access course, and two participants O’ level/O' level plus college courses. Five participants did not provide information about their educational qualifications. In terms of information on employment/occupational status among the member participants, one selected 'employed', stating 'part-time', one selected 'volunteer', one 'retired/other', specifying 'artist' and one 'full-time carer', specifying 'mother', while eight 
stated that they were not in waged employment. Apart from their formal qualifications, some member participants had attended other community- or NHS-based arts services and college courses.

Formal ethical procedures were negotiated with studio managers and involved obtaining informed consent for participation. Ethical permissions were obtained from the University of Wolverhampton School for Education Futures Research Ethics Committee.

Field work took place over eleven months. The participant observation commenced first, this being used contextually to inform subsequent interviews with members at stage two, which lasted between 30 minutes and two hours. An interim report of the findings from observations and interviews with members was fed back as an exercise in 'respondent validation', with comments received at forum meetings and via e-mail. At a third stage of field work, the interim report formed a basis for interviews with studio managers, allowing for critical analytical discussion of themes. These were around one hour in length. Field notes were written up directly following observations whereas interviews were audio recorded and transcribed. Transcripts were made available to participants upon request.

The interview data were analysed thematically using categorical indexing, working interactively between research question and data (Mason 2002). This involved bringing a critical, feminist sociological lens to bear on the data to identify themes relating to mutuality itself (such as mutual support, mutual acceptance and trust) and facilitators and barriers/challenges to the generation of mutuality between participants in the studio. The latter encompassed consideration of the social construction of power relations, particularly gender relations, and cultural and contextual factors such as identities and organizational and professional ethos. Due to time limitations, field notes were selectively analysed. Key themes arising from our analysis are set out below. Within interview excerpts, [...] indicates missing text, $[\ldots]$ an ellipsis, italics indicate emphasis and brackets indicate added text. 


\section{Findings}

Our analysis identified three main themes relating to possibilities for, and tensions associated with, generating mutuality between studio managers and members through art-making together in the study setting. One of these was concerned with the ways in which the artmaking, as a discursive and social practice, operated to either even out, construct, reinforce, obscure or challenge differences, divisions and inequalities among participants in the art studio, on the basis of organizational status and wider gender power relations. Another related to the humanistic ideal of mutual acceptance, and barriers and limits to this, within the studio, again incorporating an analytical and interpretive focus on gender, which was a salient dimension of the social setting. The third theme was personal, professional and creative 'boundaries' between participants, and how these were displayed, discussed and negotiated, particularly on the part of studio managers. In what follows, each of these themes is discussed in turn. The analysis shows how gender is central to understanding the social processes relating to mutuality in the art studio, particularly with respect to the power relations and emotional labour involved, thereby situating the social interactions studied in relation to the wider socio-political context.

\section{(De)constructing and obscuring relational asymmetries}

Making art together in the studio was seen by both members and studio managers as facilitating interaction and acting as a social leveller. One member commented that this meant, 'there's not a them and us, kind of, a dynamic that you might get, especially in mental health services'. Participants also described mutual enjoyment through the shared practice, a theme that linked to descriptions of shared learning, including between studio managers and members. An initiative involving studio members leading workshops provided an important 
opportunity for this and was considered valuable for recognizing the skills and expertise of members, many of whom were qualified artists. In addition, members took part in wider community initiatives such as exhibitions and community art-making events. These were viewed as important for one's identity as an artist and someone with 'something to offer [...] that people value', as one member put it.

Members discussed the personal value of artistic identities to them and how these related to being part of 'a community of artists'. This was viewed as helpful in taking the focus away from 'mental health problems', thereby facilitating opportunities for (re-) establishing personally and socially valued identities and counteracting the processes of social differencing associated with constructions of mental illness. One member did comment, however, that the fact that the studio nevertheless still positioned members in terms of 'mental health' and 'outsider art' (as it was a targeted mental health organization) was restrictive as it worked to perpetuate marginalization.

Artistic identities and the opportunity for art-making were also valued by studio managers, one of whom commented, 'I think it's important for any art therapist to have the identity of being an artist and I too often hear of a lot of art therapists who never have enough time to do their art and it's always said very sadly'. These reflections highlight the need for creativity among art therapists to avoid 'clinification', a syndrome involving moving from identifying as a creative artist to becoming primarily a clinician focusing on clients' individual psychopathologies rather than their creative abilities, and the associated development of feelings of emptiness and disconnection (Iliya 2014).

This interviewee also commented on the importance of everyone working in the studio sharing the identity of being an artist within their therapeutic community approach. In his view, while there was an unmovable hierarchical relation between staff and members, 'the art-making is one area where we are all equal in being artists'. This approach, he considered, 
meant that everyone could feel 'part of a community and contribute to it'. The personal value of social integration and a sense of communality through the shared art-making practice was thus also conveyed by the studio managers, another of whom felt that this generated social solidarity as 'you're both in it together' and reflected, 'It's good for me to feel I'm part of this community rather than I'm somebody who runs it'.

Another studio manager described how mutually exposing one's vulnerability through experimentation in the art-making process could help equalize their relationships with members as 'we're kind of all starting from the same position' (e.g. 'a blank [piece of] paper'). This view was also expressed by one studio manager, who felt that the process of making art together could produce feelings of shared humanity and the capability for making connections that moved people beyond binary identities based on organizational status as members or studio managers:

I think art equalizes $[\ldots]$ We're searching and we can all share that process; [...] I think it's generous, when people create together. [...] I think there's a generosity in openness and the more people struggle with their artwork the more you're getting a connection on such a deeper level. [...] To be able to feel comfortable to make work, you have to feel some trust I suppose, to open yourself, to explore.

These interviewees therefore described how the shared process of art-making required openness and trust on both sides of the relationship between studio managers and members. Their comments describe shared personal exposure and struggle and the orienting of participants to a mutual understanding and ethos (see also Froggett and Little 2012).

However, one of these studio managers also expressed the need to be careful that the generation of trust through art-making together, and associated attempts at social 'levelling' 
and forging a collective identity as artists, did not obscure the reality of different social roles and power relations within the community, as studio managers, nevertheless, occupied positions of authority. Furthermore, from observations in the studio, it was apparent that in addition to being a social leveller, art-making alongside others could also work to reinforce or (re)construct social distinctions and hierarchies. This constitutive work appeared to be taking place, for example, on occasions when a staff member was working in a different, more unusual medium compared to most members (such as sculpture in clay compared to painting and drawing) or was producing more impressive outputs. Creative products could also become a marker of status in the studio and this was reinforced through a competitive approach to participation in exhibitions, something that two female members described avoiding due to a fear of failure or having one's confidence knocked. The research therefore indicated how, in the shared art-making environment, development as an artist could be inhibited for some participants, particularly women, perhaps due to what Sen (2010) calls 'adaptive attitudes' as agency is socially conditioned and restricted, for example on the basis of gender inequality (see Lewis 2012a).

The workings of gender inequality were also evident in the sharing of studio space, with some male members being very expansive with their artwork, and reportedly in one case even impinging on a female member's composition. It was also evident in interactions between studio managers and members, particularly on one occasion when some female members were complaining about the behaviours of some male members. These observations highlight the ways in which prevailing gender dynamics in social life can cut across identities of organizational status and present a challenge to mutual ways of working and attempts at social levelling in such settings. Like the power relation between studio managers and members, these dynamics could equally be obscured by an emphasis on shared artistic identities. However, two female members used their contributions to a communal art project 
to make statements on gender politics both within the studio and more widely. As with other organizations of this nature, then, the studio could at times be a difficult, risky and contested collective space (see Parr 2006: 158-159).

\section{Mutual acceptance and its limits}

Participants' accounts often conveyed the ways in which art-making in the studio generated humanistic qualities in the setting related to personal recognition. They talked about how this shared practice enabled mutual respect and acceptance. For instance, one female member commented, 'I think there's quite a lot of respect for different ways of being, or different kind of art that's made'. On a similar note, a female studio manager reflected, 'Just because you're like this and I'm like this doesn't mean that you're right and I'm wrong, it's just that this is how we are. We all get to make art here so it's terrific'.

These extracts describe how making art in a shared space together could provide acceptance through a non-judgemental approach and recognition through affording people equality of moral worth and respect. Another studio manager explained how she felt generating this ethos was especially important in light of a very judgemental and pressurized wider social environment, meaning, in contrast, 'here we just are trying to be as real as possible and anything goes in a sense', an approach described by another manager as allowing people to be 'more human'.

Yet this ethos did not always translate unproblematically from the art-making into the social milieu of the studio. One tension was over balancing efforts towards mutual acceptance and inclusion with maintaining a conducive working environment for everybody. Again there were gender dimensions to this. Two male members described how the studio offered an environment in which potentially socially unacceptable ways of being, such as '[not] making an effort with other people' or 'somebody kick[ing] off badly', were accepted and 
understood. But, in contrast, two female members recounted preferring a 'light' emotional atmosphere and one described experiences of other creative arts mental health settings in which the low mood of others 'brought me down as well'. In addition, a female studio manager described how she had felt it necessary to challenge one male member's silence to encourage him to contribute more to the studio as a community. She also discussed the difficult balance over managing and 'containing' one male member's expressions of anger to 'make the space safe enough for everyone else to continue working' and how it 'tested me in terms of having to be authoritative' in light of efforts towards non-hierarchical practice.

These findings reflect societal gendered expectations surrounding the expression of emotion and emotion work (see Lewis 2012b), aspects of which were also observed in the studio at times. For example, male members were more likely to come in and go about their artwork in relative silence and women members to circulate and comment on other members' work or to undertake caring practices such as making drinks for others. Given that practices of mutuality often involve emotion work, the findings highlight how gender norms surround these practices. They are also a reminder of the situatedness of practices of mutuality, and attempts to manage others' emotions to encourage mutuality in such organizational settings, in wider gender-based power relations.

This analysis exposes some of the complexities involved in trying to uphold principles of mutual acceptance and inclusiveness in mental health arts settings. These principles are often associated with an inclusive approach involving efforts to tolerate disturbance and unsocial behaviour and to allow freedom of artistic expression in these settings. However, the complexities discussed above suggest that there may be a need to place limits around such principles in practice (see Secker et al. 2007; Spandler 2006).

\section{Maintaining, working with and challenging 'boundaries'}


Some of the limiting factors to mutuality in the studio involved tensions between individuals' varying needs to maintain personal boundaries. For example, some people preferred to work in their own, separate space whilst others preferred working around a shared table.

In terms of the art-making process and the content of the art being made, maintaining boundaries so as to avoid becoming too emotionally involved with others in the studio setting was a particular, recurrent theme in the accounts of the studio managers. For instance, one described how making art alongside members provided important relational opportunities in terms of openness and showing human fallibility, for example through making mistakes in their artwork and showing their frustrations, but also referred to the need to 'control' revealing too much of this 'human side'. Two others reflected, 'You have to be very, very aware of your own personal space and boundaries' and:

There's risk in making artwork in front of people and it can make you feel vulnerable and how that feels. And I agree totally about having to be quite careful about the kind of artwork that you make here; [...] I wouldn't make something that was overtly personal; [...] I feel more happy with artwork which is one layer abstracted.

The need for therapeutic boundaries was also discussed in the context of the occasional reversal of roles as members offered interpretations of studio managers' artwork (although the studio's approach was to 'provide a containing environment' for, rather than clinical interpretation of, people's artwork, as one studio manager explained it). Three of the studio managers mentioned gaining personal insight from members' comments about their own artwork. Notably, one described how this had 'changed my expectations of the clienttherapist relationship'. Yet she also felt that there could be risks for the practitioner of such a mutual approach as interpretations could be members' projections of their own personal 
experiences (something which was also the case for studio managers, of course). Another participant considered that too much close therapeutic examination of the content of studio managers' artwork could detract from the creation of a therapeutic environment for members to explore and develop their creativity and contravene members' expectations of staff. This view was reflected by one member, who, when asked about the most beneficial approach on the part of studio managers, replied, 'supportive and open-minded but don't stress their feelings, emotions onto members or burden members with their own problems'.

This indicates other possible limitations to generating mutuality through shared artmaking in such a setting. Most notably, the felt need among the studio managers to maintain personal and professional boundaries in their art-making could constrain opportunities for making humanistic connections, such as mutual recognition and trust, through this shared practice. However, the studio managers explained how, in terms of what one should 'put out there' in their artwork, 'we all have different views on that within the team' and, as described earlier, one felt that sharing the creative process could produce deep connections to others, indicating a kind of dissolving of professional boundaries through the approach. They also described how working creatively with 'boundaries' could be a constructive part of the art therapeutic process. For instance, one commented that being open to a more mutual way of working with clients was 'almost like a humility thing', and reflected, 'I think you have to be able to question what the boundaries are and why they're there'. Another remarked, 'It (making art together) might be dangerous to the therapist as well as the member [...] (but if) the therapist is thoughtful enough and trained well enough they can work with that'.

Taken together, the accounts of the studio managers demonstrated how their work involved balancing a professional ethos involving maintaining boundaries and focusing the therapeutic work on members with questioning or challenging professional boundaries, including allowing the therapeutic lens to be turned on themselves at times. Two studio 
managers described managing this tension creatively through 'mak[ing] a piece of artwork which said something about the group that day'.

In addition, the studio managers' roles also involved overseeing the studio and they discussed how practically and professionally one could not become too absorbed in one's own art-making due to the need to maintain management awareness of the dynamics on the studio as a whole and a duty of care towards members. Their roles thus involved the constant need to 'navigate' the social, creative and therapeutic terrain of the studio. One interviewee felt that the art-making itself could help manage the tension of balancing between managerial responsibilities and one's own creative process.

\section{Discussion}

The findings of this study build on previous research about mutual participation in creative activities for mental health workers and clients. Like other studies, they suggest the 'levelling' effects of this shared participation - how it can help people transcend professional-service user boundaries to just be part of a group - and how it can help forge connections between workers and other participants (Ascenso et al 2018; Callahan et al. 2017; Froggett and Little 2012; Perkins et al. 2016; Saavedra et al. 2017; Sapouna and Pamer 2016). Reflecting this previous research, the findings show the benefits of this mutual participation in generating feelings of connectedness to a shared culture and community and enhanced equality, humility, understanding, acceptance and empathic connection between clients and practitioners. They also illustrate how arts interventions can create a mutual learning experience for therapeutic or educational personnel and participants (see also Gillispie 2003; Noble 2005; Swindells et al. 2013). Our analysis therefore suggests the importance of opportunities for social inclusion, a sense of belonging and 'togetherness' among participants in mental health participatory arts 
contexts demonstrated in previous research (Goldie 2007; Parr 2006; Secker et al. 2007), can be extended to include practitioners in these settings too.

Our findings indicate that the art studio was providing opportunities not only for building supportive relationships, which are often seen as central to mental health and wellbeing (e.g. Pilgrim et al. 2009), but also for mutually constructing social recognition as artists for both studio managers and members. For members these opportunities and associated agency, or capacity for effective action in the world (Edwards 2007), were further expanded through their 'cultural citizenship' in taking part in wider creative arts community activities.

An emphasis on attempts to construct less hierarchical relationships and on mutual respect through shared art-making was a key theme that indicates how recovery and wellbeing can be supported by recognition and respect from others, especially in the face of diminished social roles or restricted opportunities. Such humanistic processes are often discussed in relation to mental health recovery (e.g. Lewis 2014; Topor et al. 2006), including in the context of arts projects (e.g. Sapouna and Pamer 2016; Spandler et al. 2007).

However, our analysis also demonstrates some of the complexities of the social processes associated with shared art-making practice in such settings, and how attempts at social 'levelling' and generating mutuality through this shared practice are not straightforward and require careful consideration. We show how while this kind of approach can work at a cultural level to lessen social divisions and to equalize social relations among participants, it can also work to (re)inscribe and reproduce social asymmetries. One important observation here was how attempts to forge collective creative identities in such settings can operate to disguise structural inequalities between workers and participants, and also the operation of wider social inequalities such as gender - even though gender power relations were also challenged by some women members. Furthermore, while a shared identity as artists worked 
to counteract social 'differencing' on the basis of mental illness identities, and the mental health targeted nature of the organization was important for combatting social exclusion for those experiencing long-term mental health issues, the fact that the studio was located in terms of mental health simultaneously risked socially marginalizing members as outsider artists or 'other' (see Parr 2006).

Other challenges and limitations to the expansion of possibilities for mutuality between members and studio managers included personal and professional boundaries, organizational responsibilities and a duty of care that required members' needs to be put first. Yet negotiating challenges regarding 'boundaries' and role navigation was considered by the studio managers to be a constructive part of the art therapeutic process and making art alongside members as a way of dealing with some of the tensions involved.

\section{Conclusion}

This study addresses a lacuna in social research on mental health participatory arts regarding mutuality between workers and participants and the relational dynamics of shared art-making practice. It also brings a critical and gender lens to the discussion of arts and health practice. The study responds empirically to calls to look beneath the surface of practices of mutuality to understand more fully the intertwining of social relationships and creative practice in mental health creative arts settings (Perkins et al. 2016). Furthermore, it addresses calls for a more critical examination of processes of 'differencing' within spaces and strategies of social inclusion through arts initiatives (Parr 2006).

The findings corroborate Brown's (2012) argument that the arts and mental health workforce should be supported to pursue their own artistic vocation and indicates possible benefits from re-examining professional boundaries in the context of participatory arts practice, both for participants and for workers (Callahan et al. 2017; see also Topor et al. 
2006). However, they also illuminate the complex dynamics generated through participants and workers making art together in such a setting that can involve difficult social and interpersonal challenges and barriers to mutual respect and vulnerability. Indeed, they show how a shared art-making approach in mental health settings generates challenges that may even have well-being 'disbenefits' for those involved. This may be a particular risk if attempts by arts and mental health staff to lower their personal and professional boundaries leave them feeling emotionally exposed or unsupported, or if this emotional exposure is considered by other participants to be burdensome. Consequently, it is important to avoid a kind of forced or expected mutuality between individuals as part of this approach. Rather, it requires careful negotiation of personal, professional, creative and organizational boundaries, with consideration and understanding of the wider social context of power relations.

The article also demonstrates the need for awareness among art practitioners working in the area of mental health of the ways in which shared art-making practices and artistic identities within an open studio approach can (re)constitute and challenge organizational and wider social relations of power and ordering. This includes awareness of the potential impacts of gender inequities on art-making activities and social interaction that may require skilful interventions and boundary-setting. It highlights the need for those working in the field to consider critically the interactive relationship between use of space and power dynamics, particularly with respect to gender, and the gendered nature of emotional expression, emotion work and care practices, and the management of emotions among participants in shared artmaking mental health settings. Future research could further explore the social dynamics, challenges, mutual benefits and 'disbenefits' of shared art-making practice among practitioners and participants in mental health participatory arts settings utilizing a contextual approach that takes account of wider social structures. As we have demonstrated, gender dynamics are likely to be salient in these settings, but future research could also consider 
other, intersecting social dynamics such as social class, age, race and ethnicity, thereby extending sociological analysis of this area.

\section{Acknowledgements}

We would like to thank the third sector organization who collaborated in this research and to thank all the interview participants who gave their time and insights and the staff members who facilitated the fieldwork. We are also grateful to those in the study setting who accommodated the participant observation. Finally, we extend our thanks to the reviewers of this article and to the assistant editor of this journal, Dr Teresa Fisher, for their helpful and thoughtful comments. We would particularly like to thank one reviewer whose comments contributed towards the conclusion.

This article draws on an unpublished final project report (Lewis et al. 2016). The project team comprised Dr Lydia Lewis (lead), Professor Helen Spandler, Professor Jerry Tew, Professor Kathryn Ecclestone, Dr Janet Wallcraft, Clare White, Howard Croft and Tony Devaney. The consortium of which this project was part was led by Professor Paul Crawford, University of Nottingham.

This research was funded by an AHRC/RCUK Connected Communities large grant, no. $\mathrm{AH} / \mathrm{K} 003364 / 1$.

\section{References}


Ascenso, S., Perkins, R., Atkins, L., Fancourt, D. and Williamon, A. (2018), 'Promoting well-being through group drumming with mental health service users and their carers', International Journal of Qualitative Studies on Health and Well-being, 13:1.

Australasian Therapeutic Communities Association (2017), 'The TC Model and Principles for TC Leaders', unpaginated, http://www.atca.com.au/modules/modules/the-tcsector/the-tc-model-and-principles-for-tc-leaders/. Accessed 3 March 2018.

Brookfield, S. (2005), Becoming a Critically Reflective Teacher, San Francisco: Jossey Bass.

Brown, L. (2012), 'Is art therapy?', in T. Stickley (ed.), Qualitative Research in Arts and Mental Health, Ross-on Wye: PCCS Books, pp. 22-41.

Callahan, K., Schlozman, S., Beresin, E. and Crawford, P. (2017), 'The use of music in mutual recovery: A qualitative pilot study', Journal of Applied Arts and Health, 8:1, pp. 103-14.

Crawford, P., Hogan, S., Wilson, M., Williamon, A., Manning, N., Brown, B. and Lewis, L. (2018), Creative Practice as Mutual Recovery: Research Programme Final Report, University of Nottingham, April. 
Edwards, A. (2007), 'Working Collaboratively to Build Resilience: A CHAT Approach', Social Policy and Society, 6:2, pp. 255-264.

Froggett, L. and Little, R. M. (2012), 'Dance as a complex intervention in an acute mental health setting: A place :in-between', British Journal of Occupational Therapy, 75:2, pp. 93-99.

Gillispie, C. (2003), 'Poetry therapy techniques applied to a recreation/adult education group for the mentally ill', Journal of Poetry Therapy, 16:2, pp. 97-106.

Goldie, I. (2007), Arts, Creativity and Mental Health Initiative: Participatory Arts Self Evaluation Approach Project Report, London: MHF.

Iliya, Y. A. (2014), 'The purpose and importance of personal creativity for creative arts therapists: A brief literature review', Journal of Applied Arts and Health, 5:1, pp. 10915.

Lewis, L. (2012a), 'The capabilities approach, adult community learning and mental health', Community Development Journal, 47:4, pp. 522-37.

(2012b), “It's people's whole lives": Gender, class and the emotion work of user involvement in mental health services', Gender, Work and Organisation, 19:3, pp. $276-305$. 
(2014), 'Responding to the mental health and wellbeing agenda in adult community learning', Journal of Research in Post-Compulsory Education, 19:4, pp. 357-77.

Lewis, L., Spandler, H., Tew, J. and Ecclestone, K. with Croft, H. (2016), Mutuality, Wellbeing and Mental Health Recovery: Exploring the Roles of Creative Arts Adult Community Learning \& Participatory Arts Initiatives, Final Research Report, University of Wolverhampton, April.

Mason, J. (2002), Qualitative Researching, 2nd ed., London: Sage.

Noble, S. (2005), 'Mental illness through popular theatre: Performing (in)sanely', New Directions for Adult and Continuing Education, 107, pp. 45-53.

Parr, H. (2006), 'Mental health, the arts and belongings', Transactions of the Institute of British Geographers, 31:2, pp. 150-66.

(2012), 'The arts and mental health: Creativity and inclusion', in T. Stickley (ed.), Qualitative Research in Arts and Mental Health, Ross-on Wye: PCCS Books, pp. 121. 
Perkins, R., Ascenso, S., Atkins, L., Fancourt, D. and Williamon, A. (2016), 'Making music for mental health: How group drumming mediates recovery', Psychology of Wellbeing, 6:11, pp. 1-17.

Pilgrim, D., Rogers, A. and Bentall, R. (2009), 'The centrality of personal relationships in the creation and amelioration of mental health problems: The current interdisciplinary case', Health, 13:2, pp. 235-54.

Saavedra, J., Arias, S., Crawford, P. and Pérez, E. (2017), 'Impact of creative workshops for people with severe mental health problems: Art as a means of recovery', Arts and Health, 10:3, pp. 241-56.

Sapouna, L. and Pamer, E. (2012), Beyond Diagnosis: The transformative Potential of the Arts in Mental Health Recovery, research report, School of Applied Social Studies, University College Cork.

(2016), 'The transformative potential of the arts in mental health recovery - an Irish research project', Arts and Health, 8:1, pp. 1-12.

Secker, J., Hacking, S., Spandler, H., Kent, L. and Shenton, J. (2007), Mental Health, Social Inclusion and Arts: Developing the Evidence Base, Final Report, London: NSIP/CSIP.

Sen, A. (2010), The Idea of Justice, London: Penguin Books. 
Spandler, H. (2006), Asylum to Action, London: Jessica Kingsley Publishers.

Spandler, H., Secker, J., Kent, L., Hacking, S. and Shenton, J. (2007), 'Catching life: The contribution of arts initiatives to "recovery" approaches in mental health', Journal of Psychiatric and Mental Health Nursing, 14:8, pp. 791-99.

Stickley, T. (2010), 'The arts identity and belonging: A longitudinal study', Arts and Health, $2: 1$, pp. $23-32$.

Swindells, R., Lawthom, R., Rowley, K., Siddiquee, A., Kilroy, A. and Kagan, C. (2013), 'Eudaimonic well-being and community arts participation', Perspectives in Public Health, 133:1, pp. 60-65.

Topor A., Borg, M., Mezzina, R., Sells, D., Marin, I. and Davidson, L. (2006), 'Others: The role of family, friends and professionals in the recovery process', American Journal of Psychiatric Rehabilitation, 9:1, pp. 17-37.

\section{Contributor details}

Dr Lydia Lewis is a research fellow in the Institute of Education, Faculty of Education, Health and Wellbeing, University of Wolverhampton. Her research work focuses on theoretically informed, applied sociological inquiry and knowledge exchange with third sector organizations. She has developed a programme of research on education and mental health, with a particular focus on adult community learning (ACL). Her most recent study has 
explored creative practices and mutuality in ACL and participatory arts settings as part of a consortium programme of research - see http://www.healthhumanities.org/creative_practice_mutual_recovery/.

Dr Helen Spandler is professor of mental health studies at the University of Central Lancashire. She is a qualitative researcher in mental health, critical social theory and policy and has completed numerous national and regional research projects. Her books include Distress or Disability?: Mental Health and the Politics of Disablement (2015); Beyond Fear and Control: Working with Young People Who Self-Harm (2007); Asylum to Action: Paddington Day Hospital, Therapeutic Communities and Beyond (2006); and Who's Hurting Who? (1996). She is the Managing Editor of Asylum: The Magazine for Democratic Psychiatry.

Contact:

Lydia Lewis, Institute of Education, University of Wolverhampton, Walsall Campus, Gorway Road, Walsall WS1 3BD, UK.

E-mail: Lydia.lewis@wlv.ac.uk

ORCID: 0000-0002-7529-8249

Helen Spandler, School of Social Work, Care and Community, UCLan, Harrington Building, HA225, Preston, Lancashire, PR1 2H, UK.

E-mail: hspandler@uclan.ac.uk https://orcid.org/ 